Results The musculoskeletal symptom and work ability among the intervention group at post intervention were illustrated the marginal changes trend. This study found that sick leave among orderlies in the intervention group did not decrease. An explanation for the lack of decreased sick leave is that physical risk factors were addressed during the intervention period. During short follow up ( 2 months), the positive outcome of the PEIP program within the intervention group had proven by the number of health outcomes achievements carried out by orderlies. QEC scores were found illustrated the marginal changes trend for the lower back, hips/thighs and then upper back among the intervention group at post intervention, whereas the scores for the shoulder/arm, wrist/hand and neck were not found the marginal changes trend for static use and moderate for moving.

Discussion This study suggests that the substantial improvements in work environments and health outcomes among healthcare worker were seen following participatory ergonomic (PE) approach.

\section{A MULTIDISCIPLINARY CASE STUDY TO OPTIMISE ERGONOMIC WORK CONDITIONS IN A NEW DISTRIBUTION CENTRE AT THE WORLD'S LEADING SPORTS BRAND}

${ }^{1} \mathrm{~N}$ Maes, ${ }^{2} \mathrm{G}$ Pollentier ${ }^{*},{ }^{2} \mathrm{~S}$ Acke, ${ }^{2} \mathrm{E}$ Verbeek, ${ }^{2} \mathrm{D}$ Delaruelle, ${ }^{2} \mathrm{~K}$ Eerdekens, ${ }^{2} \mathrm{M}$ N Schmickler. 'Department of Health, Safety and Environmental Risks, Nike, Belgium; ${ }^{2}$ Mensura Occupational Health Services, Belgium

10.1136/oemed-2018-ICOHabstracts.785

Introduction Discharging a container/trailer is physically very stressful. This study describes a multidisciplinary and solutions oriented approach in a newly constructed Distribution Centre (DC).

Methods The setting is the European DC of a sports brand with 2,205 Belgian operators. The project is focused on innovative solutions for the area where the receiving of footwear is done. Repetitive movements and lifting resulted in musculoskeletal complaints that were reported to the occupational physician via the yearly Nordic Musculoskeletal questionnaire surveillance.

The ergonomist implemented the following four-step multidisciplinary approach:

- Risk stratification (employee, equipment, environment, product and organisation)

- External workload evaluation (task analysis/observation, Key Indicator Method (KIM), ISO 11228 standard, noise and illumination)

- Internal physical workload examination (heart rate)

- Participatory subjective work perception index

Results The important results of the external workload evaluation are described below:

a. Observation. The ergonomic 'manrider' tool needs additional ergonomic improvements.

b. KIM. Women doing the receiving for 3.5 to 7.25 hours scored 55: 'Heavy workload: physical overload is likely. Workplace re-design is necessary.' Men scored 45: 'Strongly increased workload; physical overload is possible. Workplace re-design is recommended.'

c. ISO 11228. The recommended weight limit (RWL) at the end of the shift for men/women with a height of $148 \mathrm{~cm}$ was 2.03; for women with a height of $180 \mathrm{~cm}$, the RWL was 1.99; and for men with a height of $195 \mathrm{~cm}$, the RWL was 1.98. The Lift-Index for these groups was 3.46, 3.53 and 3.55 , respectively, resulting in a higher risk for lower back pain.

d. Illumination at the end of the trailer was 192 and 308 lux. At the end of the container, 32.1, 11.7, 11, 11.3 and 43.3 lux was measured. The NBN-EN 12464-1 standard for illumination (minimum 200 lux) was insufficiently achieved.

Discussion A multidisciplinary approach is recommended to optimise ergonomic work conditions.

\section{RHIZARTHROSIS IN BANKNOTE PROCESSING WORKERS: A RETROSPECTIVE COHORT STUDY}

${ }^{1} \mathrm{G}$ Verrijdt, ${ }^{2} \mathrm{~A}$ De Landtsheer*, ${ }^{1} \mathrm{~A}-\mathrm{M}$ Mellen, ${ }^{3} \mathrm{~L}$ Godderis. ${ }^{1}$ FEDRIS Federal Agency for Occupational Risks, Brussels, Belgium; ${ }^{2}$ National Bank of Belgium Occupational Health Department, Brussels, Belgium; ${ }^{3} \mathrm{KU}$ Leuven University Environment and Health department, Leuven, Belgium

\subsection{6/oemed-2018-ICOHabstracts.786}

Introduction Rhizarthrosis is a common condition affecting $10 \%$ to $30 \%$ of the population over the age of 60 . Whether or not it is an occupational disease has been the subject of debate as epidemiological studies on the correlation between physical stress and the presence of rhizarthrosis have shown conflicting results. A cluster of cases among banknote processing workers was reported by the OHP to the Federal Agency for Occupational Risks for evaluation

Methods We have set up a retrospective cohort study covering195 employees currently or previously involved in the manual or automated processing of banknotes. Each participant's job history was carefully reconstructed and the number of months holding certain job titles determined. Each participant was clinically and radiologically examined for the presence of rhizarthrosis in both hands, scored by a combination of clinical and radiological criteria and related to exposure.

Results The prevalence of rhizarthrosis was $27 \%$ in female participants (mean age: $52.3 \mathrm{y} \pm 4.4 \mathrm{y}$ ) and $17 \%$ in male participants (mean age: $53.2 \pm 5.8 \mathrm{y}$ ). The odds ratio for rhizarthrosis after 10 years' full-time overall exposure was significantly higher (OR10y: 1.53 (1.03-2.28)). Surprisingly, one particular job, 'manual counting', described by participants as highly straining and severely taxing on the thumbs, has not shown any significantly higher prevalence of rhizarthrosis.

Conclusion Our study has confirmed the correlation between the presence of rhizarthrosis and age, gender and manual repetitive work. We found a significantly higher risk for banknote processing in general but not for one particular job ('manual counting'), although considered by participants as a strenuous effort for the thumbs.

Discussion This is the first study on the risk of developing rhizarthrosis in banknote processing workers. The result indicates they are at greater risk and calls for adequate occupational health monitoring to prevent irreversible damage to the CMC-1 joint. 